\title{
Non-contact mobility measurements of graphene on silicon carbide
}

Whelan, Patrick Rebsdorf; Zhao, Xiaojing; Pasternak, Iwona; Strupinski, Wlodek; Jepsen, Peter Uhd; Bøggild, Peter

Published in:

Microelectronic Engineering

Link to article, DOI:

10.1016/j.mee.2019.03.022

Publication date:

2019

Document Version

Peer reviewed version

Link back to DTU Orbit

Citation (APA):

Whelan, P. R., Zhao, X., Pasternak, I., Strupinski, W., Jepsen, P. U., \& Bøggild, P. (2019). Non-contact mobility measurements of graphene on silicon carbide. Microelectronic Engineering, 212, 9-12.

https://doi.org/10.1016/j.mee.2019.03.022

\section{General rights}

Copyright and moral rights for the publications made accessible in the public portal are retained by the authors and/or other copyright owners and it is a condition of accessing publications that users recognise and abide by the legal requirements associated with these rights.

- Users may download and print one copy of any publication from the public portal for the purpose of private study or research.

- You may not further distribute the material or use it for any profit-making activity or commercial gain

- You may freely distribute the URL identifying the publication in the public portal

If you believe that this document breaches copyright please contact us providing details, and we will remove access to the work immediately and investigate your claim. 


\section{Accepted Manuscript}

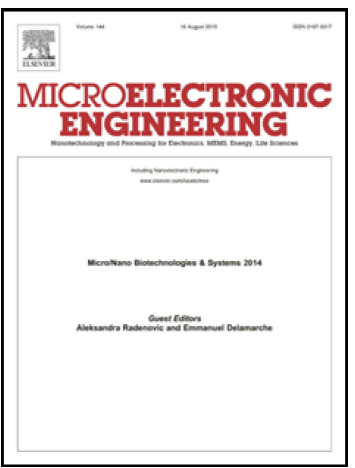

Patrick R. Whelan, Xiaojing Zhao, Iwona Pasternak, Wlodek

Strupinski, Peter U. Jepsen, Peter Bøggild

PII: $\quad$ S0167-9317(19)30064-4

DOI: $\quad$ https://doi.org/10.1016/j.mee.2019.03.022

Reference: $\quad$ MEE 10940

To appear in: $\quad$ Microelectronic Engineering

Received date: $\quad 7$ November 2018

Revised date: $\quad 13$ March 2019

Accepted date: $\quad 26$ March 2019

Please cite this article as: P.R. Whelan, X. Zhao, I. Pasternak, et al., Non-contact mobility measurements of graphene on silicon carbide, Microelectronic Engineering, https://doi.org/10.1016/j.mee.2019.03.022

This is a PDF file of an unedited manuscript that has been accepted for publication. As a service to our customers we are providing this early version of the manuscript. The manuscript will undergo copyediting, typesetting, and review of the resulting proof before it is published in its final form. Please note that during the production process errors may be discovered which could affect the content, and all legal disclaimers that apply to the journal pertain. 


\title{
Non-contact mobility measurements of graphene on silicon carbide
}

Patrick R. Whelan ${ }^{1, *}$ patwhe@ @anotech.dtu.dk, Xiaojing Zhao' ${ }^{1}$, Iwona Pasternak ${ }^{2}$, Wlodek Strupinski², Peter U. Jepsen ${ }^{1,3}$, and Peter Bøggild ${ }^{1, *}$ peter.boggild@ @anotech.dtu.dk

${ }^{1}$ Center for Nanostructured Graphene (CNG), Technical University of Denmark, Ørsteds Plads 345C, DK-2800 Kgs. Lyngby, Denmark

${ }^{2}$ Faculty of Physics, Warsaw University of Technology, Koszykowa 75, 00-662 Warsaw, Poland ${ }^{3}$ DTU Fotonik, Technical University of Denmark, Ørsteds Plads 343, DK-2800 Kgs. Lyngby, Denmark

${ }^{*}$ Corresponding author.

\begin{abstract}
Non-invasive measurement techniques are of utmost importance for characterization of atomically thin materials to speed up the measurement process while avoiding mechanical damage or contamination of the fragile materials. Terahertz time-domain spectroscopy (THz-TDS) provides non-contact measurement of the frequency dependent conductivity of thin films. Here, we expand the applicability of THz-TDS by spatially mapping the carrier density and mobility of epitaxial graphene grown on silicon carbide. The extracted values are compared to Hall measurements and agrees well for homogeneously conducting samples.
\end{abstract}

Keywords: Epitaxial graphene, Metrology, Terahertz time-domain spectroscopy, Mobility, Hall measurement, 2D materials 


\section{Introduction}

Chemical vapor deposition (CVD) of graphene directly on insulating substrates such as silicon carbide (SiC) $[1-4]$ avoids the transfer process required for metal catalyzed graphene growth $[5,6]$, which tends to hamper the electrical properties due to transfer related contaminations and defects [7-10]. Nondestructive measurements of the electrical properties of graphene on $\mathrm{SiC}$ is a requirement for applications in electronics and integrated circuits [11-14]. Non-contact methods exist for measuring the conductivity of the synthesized graphene on $\mathrm{SiC}$ such as microwave impedance and terahertz timedomain spectroscopy (THz-TDS) [15-17]. However, for high frequency applications the carrier mobility is also an important parameter [14], which is commonly determined after lithographic definition of metallic contacts onto the graphene $[18,19]$ followed by measurements with a probe station.

Here we show that it is possible to extract the carrier density and mobility of graphene directly on the $\mathrm{SiC}$ growth substrate using non-contact THz-TDS transmission-mode measurements. Conventional Hall measurements were performed to verify the measurements extracted from THz-TDS. Atomic force microscopy (AFM) and Kelvin Probe force microscopy (KPFM) was conducted to assess the SiC surface topography and measure the graphene surface potential. Considering the on-going work on improving THz-TDS reflection-mode measurements for graphene characterization [20,21], the results presented here could potentially prove useful for future in-situ characterization of graphene during CVD synthesis.

\section{Methods}

Graphene was grown by CVD on the Si-face of nominally on-axis $6 \mathrm{H}-\mathrm{SiC}$ in a hot-wall Aixtron G5 reactor and subsequently intercalated with hydrogen to obtain quasi-freestanding graphene. The details of the graphene growth process is described in detail elsewhere $[3,17]$. The thickness of the $\mathrm{SiC}$ substrates was $495 \mu \mathrm{m}$.

The samples were measured by THz-TDS in order to extract the DC conductivity $\left(\sigma_{\mathrm{DC}}\right)$, scattering time $(\tau)$, carrier density $(n)$, and carrier mobility $(\mu)$ [22-24]. The THz-TDS measurements were conducted in transmission mode using commercially available equipment (Picometrix T-Ray 4000) by scanning the samples in the focal plane of an incident $\mathrm{THz}$ beam between a $\mathrm{THz}$ transmitter and receiver, see schematic in Supplementary Fig. S1 $[17,25]$. The spotsize (full width at half max) is $\sim 350 \mu \mathrm{m}$ at $1 \mathrm{THz}$. The frequency dependent sheet conductivity $\left(\sigma_{\mathrm{s}}(\omega)\right)$ is extracted as [26]

$$
\sigma_{\mathrm{s}}(\omega)=\frac{n_{\mathrm{SiC}}+1}{Z_{0}}\left(\frac{1}{T_{\mathrm{film}}(\omega)}-1\right)
$$


where $T_{\text {film }}$ is the transmission function (ratio of Fourier transform of $\mathrm{THz}$ waveforms transmitted through graphene-covered $\mathrm{SiC}$ and a $\mathrm{SiC}$ reference sample) for the part of the time-domain signal transmitted directly through the sample, $n_{\mathrm{SiC}}$ is the refractive index of $6 \mathrm{H}-\mathrm{SiC}$ and $Z_{0}$ is the vacuum impedance. $\sigma_{\mathrm{DC}}$ is extracted by fitting the real part of $\sigma_{\mathrm{s}}(\omega)$ from $0.3-1.2 \mathrm{THz}$ to the Drude model, $\sigma_{1}(\omega)=\sigma_{\mathrm{DC}} /(1-i \omega \tau)[22,23]$. The measurements of $\sigma_{\mathrm{DC}}$ and $\tau$ are used to calculate $n$ and $\mu$ from the relations [22-24]

$$
n=\frac{\pi \hbar^{2}}{e^{4} v_{F}^{2}}\left(\frac{\sigma_{\mathrm{DC}}}{\tau}\right)^{2}, \mu=\frac{\sigma_{\mathrm{DC}}}{e n},
$$

where $v_{F}$ is the Fermi velocity set to $1.15 \cdot 10^{6} \mathrm{~m} / \mathrm{s}$ for graphene on $\operatorname{SiC}[27,28]$. The values of $n$ and $\mu$ were discarded in pixels where the $\mathrm{R}^{2}$-value of the fit to the Drude model is below 0.95 . The resulting ensemble of $n$ and $\mu$ data from each sample was fitted to $t$ location-scale distributions where the location parameter (equal to median value) is used for comparison with values from Hall measurements. Additional fitting parameters are shown in Supplementary Information.

Hall effect measurements were conducted using an Ecopia HMS3000 Hall Measurement System with a $0.55 \mathrm{~T}$ magnet. Samples were contacted in each corner using golden pins in order to measure the sheet resistance $\left(R_{\mathrm{s}}\right)$ using the van der Pauw method [29], and subsequently extract the Hall carrier density $\left(n_{\mathrm{H}}\right)$ and Hall mobility $\left(\mu_{\mathrm{H}}\right)[19]$.

AFM and KPFM measurements were performed on an NT-MDT NTEGRA Aura SPM Platform using standard conductive HA_FM/W2C probes with $20-30 \mathrm{~nm} \mathrm{~W}_{2} \mathrm{C}$ tip side coating and $<35 \mathrm{~nm}$ tip curvature radius. AFM topography was acquired on the forward pass, while the KPFM surface potential was measured on the return pass. A frequency-modulated (FM) KPFM mode was applied for KPFM measurements due to its higher spatial resolution compared to amplitude-modulated (AM) KPFM [30].

\section{Results and Discussion}

THz-TDS measurements were conducted with a step size of $200 \mu \mathrm{m}$ on two different samples (S1 and $\mathrm{S} 2$, each $15 \times 15 \mathrm{~mm}^{2}$ ) of graphene grown on SiC. The frequency-dependent conductivity (Fig. 1a) was extracted from each measurement pixel from both samples and was subsequently fitted to the Drudemodel to determine $\sigma_{\mathrm{DC}}$ and $\tau$. Sheet conductivity maps of the two samples are shown in Fig. 1(b,c). The sheet conductivity is more uniformly distributed in S1 compared to S2 where the sheet conductivity varies by a factor of $\sim 3$ across the sample. 

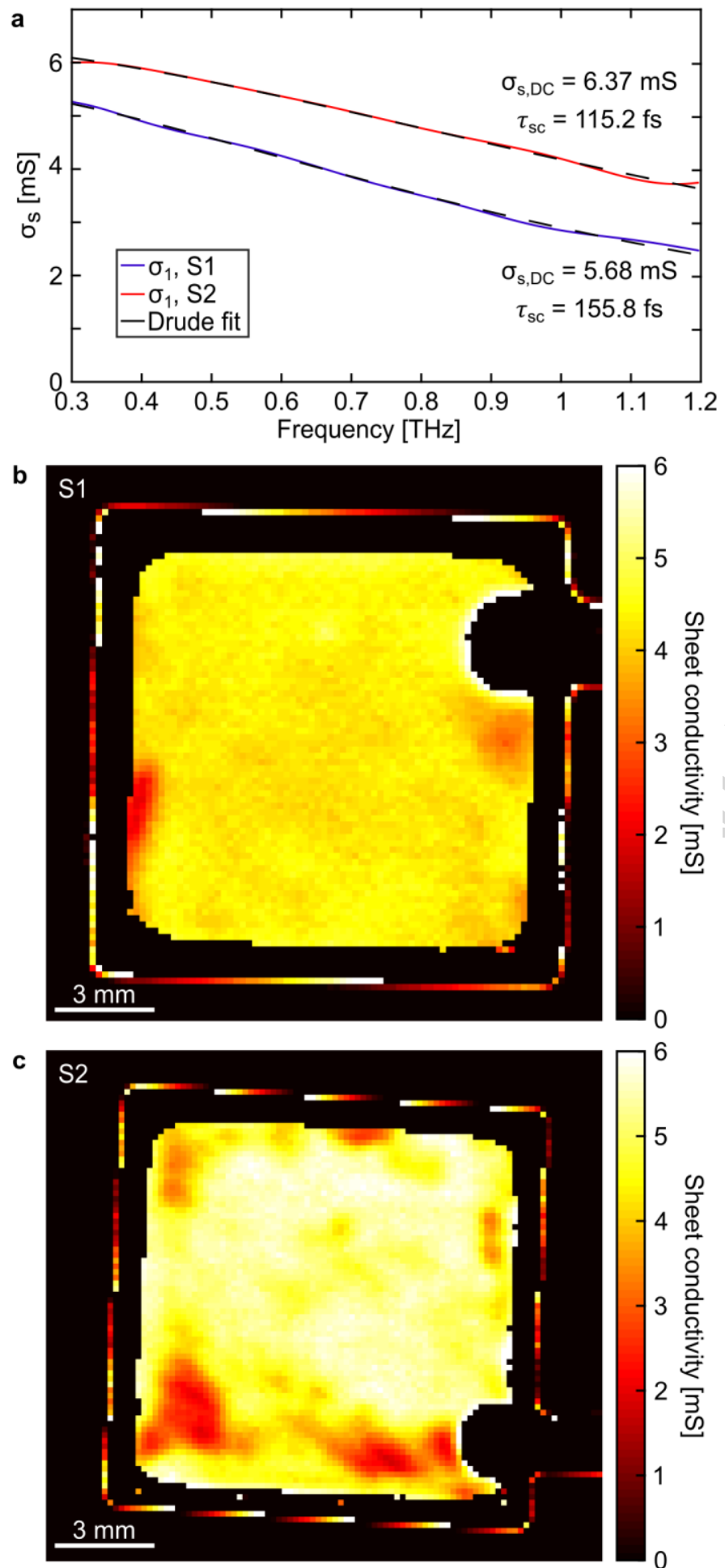

Figure 1: (a) Sheet conductivity spectra for graphene on $\mathrm{SiC}$ from two different samples (S1 and S2) together with fits to the Drude model. (b,c) Sheet conductivity maps of $\sigma_{1}$ averaged from $0.5-0.6 \mathrm{THz}$ for sample (b) S1 and (c) S2. 
We calculated $n$ and $\mu$ for each measurement pixel from S1 and S2. Maps of $n$ and $\mu$ for S1 and S2 are shown in Supplementary Fig. S2. Histograms of $n$ and $\mu$ for all the measurement pixels for S1 and S2 shows that the carrier density is lower and the mobility higher for the more homogeneously conducting $\mathrm{S} 1$ compared to S2 (Fig. 2). For S1 we find $n=6.48 \cdot 10^{12} \mathrm{~cm}^{-2}$ and $\mu=5326 \mathrm{~cm}^{2} / \mathrm{Vs}$ compared to Hall values of $n_{\mathrm{H}}=8.00 \cdot 10^{12} \mathrm{~cm}^{-2}$ and $\mu_{\mathrm{H}}=5720 \mathrm{~cm}^{2} / \mathrm{Vs}$. For S2 we find $n=9.37 \cdot 10^{12} \mathrm{~cm}^{-2}$ and $\mu=4365$ $\mathrm{cm}^{2} / \mathrm{Vs}$ compared to Hall values of $n_{\mathrm{H}}=8.55 \cdot 10^{12} \mathrm{~cm}^{-2}$ and $\mu_{\mathrm{H}}=3413 \mathrm{~cm}^{2} / \mathrm{Vs}$. The deviation of $28 \%$ for the mobility from the Hall measurement relative to the THz-TDS measurement for S2 is similar to previously reported values (33\%), while the agreement between $n\left(n / n_{\mathrm{H}}=0.81\right)$ and $\mu\left(\mu / \mu_{\mathrm{H}}=0.93\right)$ when comparing Hall and THz-TDS measurements for S1 is much better compared to previous measurements [22]. The larger deviation between values measured by Hall and THz-TDS measurements for S2 compared to S1 is likely to relate to the more inhomogeneous conductivity landscape for S2 mapped in Fig. 1c. The Hall measurement provides a single value that to a certain extent can be regarded as a weighted average over the entire $15 \times 15 \mathrm{~mm}^{2}$ sample [31,32]. Since the electrical current flows from source to drain along paths of least resistance, and not necessarily equally through all parts of the sample area, electrical measurements are fundamentally more sensitive to microscale non-uniformities compared to THz-TDS measurements [23].
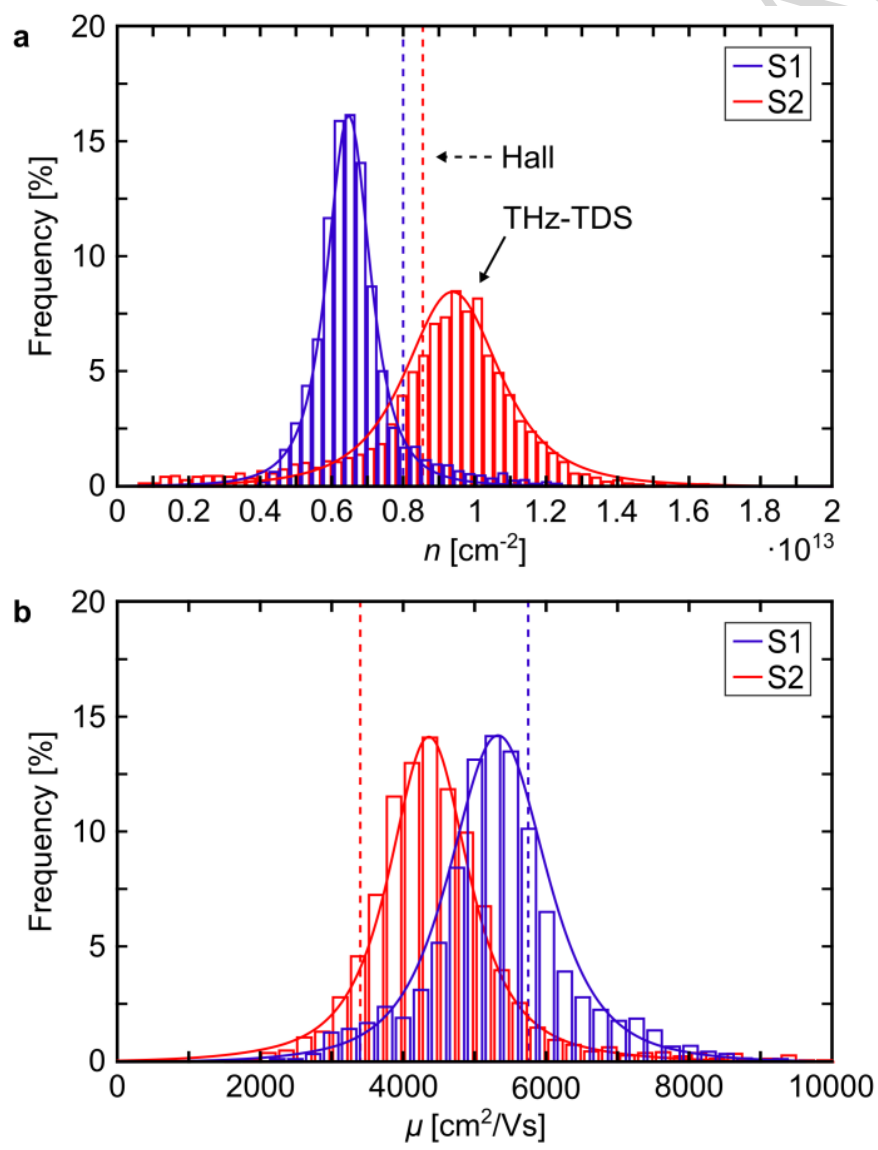

Figure 2: (a) Histogram of carrier density from THz-TDS measurement. (b) Histogram of carrier mobility from THz-TDS measurement. Dashed lines highlight values from Hall measurements, while full lines highlight fitted $t$ location-scale distributions (fitting parameters shown in Supplementary Table S1). 
AFM and KPFM measurements (Fig. 3 and Supplementary Fig. S3) were conducted on S1 and S2 to understand the differences in the electrical properties from the two samples measured by THz-TDS. A recent study links differences in the surface morphology of the SiC substrate to conductivity variations in the graphene layer and it was found that the highest quality graphene was grown on regions of the $\mathrm{SiC}$ substrate with well-defined terraces and shallow step edges [17]. In the present work, we find from AFM (Fig. 3) that the surface of S1 consists of well-defined terraces and steps. In contrast, the topography of S2 is less ordered and additionally that the sample is severely contaminated with particulates compared to the cleaner surface seen from S1. The same trend was observed by comparing AFM images from other regions on the two samples. The exact nature of the particulates was not determined, but since graphene is extremely sensitive to environmental variations [33-35], the differences in electrical properties between S1 and S2 may well be related to the different degree of contamination observed on the two samples as well as the variation in substrate topography. The fact that we measure a lower mobility from the contaminated S2 with a more disordered substrate surface compared to $\mathrm{S} 1$ is consistent with our expectations. 
a

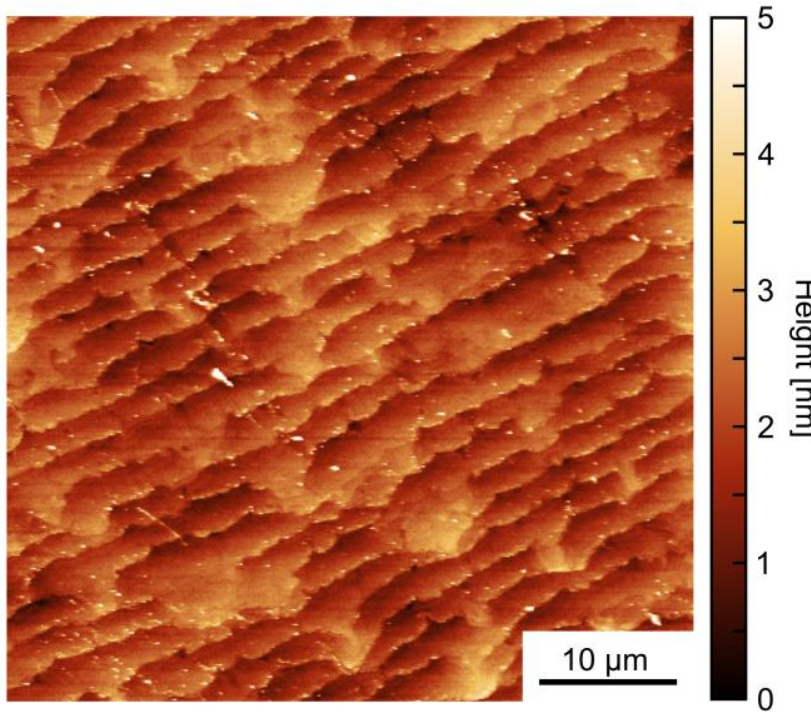

b

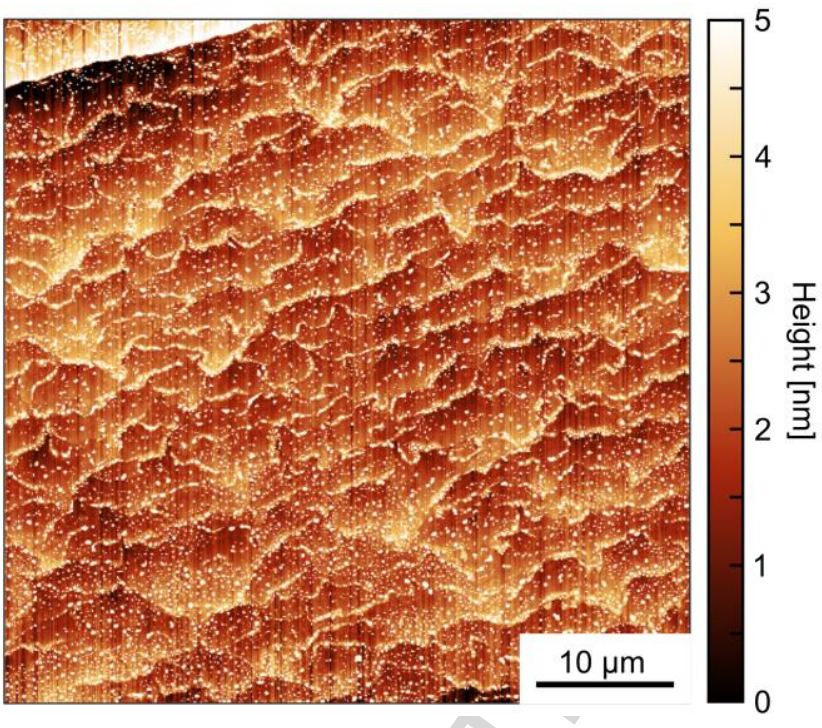

Figure 3: AFM images of (a) sample $S 1$ and (b) sample S2.

\section{Conclusion}

THz-TDS was performed on graphene on $\mathrm{SiC}$ to measure $n$ and $\mu$ using a non-invasive measurement technique. The validity of the measurement was benchmarked by performing Hall measurements on the samples. We find a good agreement between $n$ and $\mu$ from both measurements $\left(n / n_{\mathrm{H}}=0.81, \mu / \mu_{\mathrm{H}}\right.$ $=0.93$ ) when the sample is homogeneously conducting, while the THz-TDS and Hall measurements deviate more, as expected, when the sample is less homogeneous.

\section{Acknowledgements}

The authors acknowledge funding from the Danish National Research Foundation (DNRF) Center for Nanostructured Graphene (DNRF103); the EU Graphene Flagship Core 1 (grant agreement: 696656); 
the EU Graphene Flagship Core 2 (grant agreement: 785219); DFF-EDGE (grant agreement: 418400030). 


\section{References}

[1] J. Hwang, V.B. Shields, C.I. Thomas, S. Shivaraman, D. Hao, M. Kim, A.R. Woll, G.S. Tompa, M.G. Spencer, Epitaxial growth of graphitic carbon on C-face $\mathrm{SiC}$ and sapphire by chemical vapor deposition (CVD), J. Cryst. Growth. 312 (2010) 3219-3224. doi:10.1016/j.jcrysgro.2010.07.046.

[2] A. Michon, S. Vézian, A. Ouerghi, M. Zielinski, T. Chassagne, M. Portail, Direct growth of few-layer graphene on $6 \mathrm{H}-\mathrm{SiC}$ and $3 \mathrm{C}-\mathrm{SiC} / \mathrm{Si}$ via propane chemical vapor deposition, Appl. Phys. Lett. 97 (2010) 171909. doi:10.1063/1.3503972.

[3] W. Strupinski, K. Grodecki, A. Wysmolek, R. Stepniewski, T. Szkopek, P.E. Gaskell, A. Grüneis, D. Haberer, R. Bozek, J. Krupka, J.M. Baranowski, Graphene epitaxy by chemical vapor deposition on SiC, Nano Lett. 11 (2011) 1786-1791. doi:10.1021/nl200390e.

[4] Q. Liu, C. Yu, Z. He, G. Gu, J. Wang, C. Zhou, J. Guo, X. Gao, Z. Feng, Chemical vapor deposition graphene of high mobility by gradient growth method on an 4H-SiC $\left(\begin{array}{llll}0 & 0 & 0 & 1\end{array}\right)$ substrate, Appl. Surf. Sci. 454 (2018) 68-73. doi:10.1016/j.apsusc.2018.05.131.

[5] X. Li, W. Cai, J. An, S. Kim, J. Nah, D. Yang, R. Piner, A. Velamakanni, I. Jung, E. Tutuc, S.K. Banerjee, L. Colombo, R.S. Ruoff, Large area synthesis of high quality and uniform graphene films on copper foils, Science. 324 (2009) 1312-1314. doi:10.1126/science.1171245.

[6] B. Luo, J.M. Caridad, P.R. Whelan, J.D. Thomsen, D.M.A. Mackenzie, A. Grubišić Čabo, S.K. Mahatha, M. Bianchi, P. Hofmann, P.U. Jepsen, P. Bøggild, T.J. Booth, Sputtering an exterior metal coating on copper enclosure for large-scale growth of single-crystalline graphene, 2D Mater. 4 (2017) 045017. doi:10.1088/2053-1583/aa85d5.

[7] X. Liang, B.A. Sperling, I. Calizo, G. Cheng, C.A. Hacker, Q. Zhang, Y. Obeng, K. Yan, H. Peng, Q. Li, X. Zhu, H. Yuan, A.R. Hight Walker, Z. Liu, L.M. Peng, C.A. Richter, Toward clean and crackless transfer of graphene, ACS Nano. 5 (2011) 9144-9153. doi:10.1021/nn203377t.

[8] J. Chan, A. Venugopal, A. Pirkle, S. McDonnell, D. Hinojos, C.W. Magnuson, R.S. Ruoff, L. Colombo, R.M. Wallace, E.M. Vogel, Reducing extrinsic performance-limiting factors in graphene grown by chemical vapor deposition, ACS Nano. 6 (2012) 3224-3229. doi:10.1021/nn300107f.

[9] T. Hallam, N.C. Berner, C. Yim, G.S. Duesberg, Strain, Bubbles, Dirt, and Folds: A Study of Graphene Polymer-Assisted Transfer, Adv. Mater. Interfaces. 1 (2014) 1-7. doi:10.1002/admi.201400115.

[10] G. Lupina, J. Kitzmann, I. Costina, M. Lukosius, C. Wenger, A. Wolff, I. Pasternak, A. Krajewska, W. Strupinski, S. Vaziri, O. Mikael, S. Kataria, A. Gahoi, M.C. Lemme, G. Ruhl, G. Zoth, O. Luxenhofer, Residual Metallic Contamination of Transferred Chemical Vapor Deposited Graphene, ACS Nano. 9 (2015) 4776-4785. doi:10.1021/acsnano.5b01261.

[11] H. Tian, Y. Yang, D. Xie, Y.-L. Cui, W.-T. Mi, Y. Zhang, T.-L. Ren, Wafer-Scale Integration of Graphene-based Electronic, Optoelectronic and Electroacoustic Devices, Sci. Rep. 4 (2015) 3598. doi:10.1038/srep03598.

[12] M. Winters, E.O. Sveinbjörnsson, C. Melios, O. Kazakova, W. Strupiński, N. Rorsman, Characterization and physical modeling of MOS capacitors in epitaxial graphene monolayers and bilayers on 6H-SiC, AIP Adv. 6 (2016) 085010. doi:10.1063/1.4961361.

[13] X. Yang, A. Vorobiev, A. Generalov, M.A. Andersson, J. Stake, A flexible graphene terahertz detector, Appl. Phys. Lett. 111 (2017) 021102. doi:10.1063/1.4993434.

[14] O. Habibpour, Z.S. He, W. Strupinski, N. Rorsman, H. Zirath, Wafer scale millimeter-wave integrated circuits based on epitaxial graphene in high data rate communication, Sci. Rep. 7 
(2017) 41828. doi:10.1038/srep41828.

[15] J. Krupka, W. Strupinski, Measurements of the sheet resistance and conductivity of thin epitaxial graphene and SiC films, Appl. Phys. Lett. 96 (2010) 082101. doi:10.1063/1.3327334.

[16] J. Chen, Q. Liu, J. Gallop, L. Hao, Microwave method for high-frequency properties of graphene, IET Circuits, Devices Syst. 9 (2015) 397-402. doi:10.1049/iet-cds.2015.0114.

[17] P.R. Whelan, V. Panchal, D.H. Petersen, D.M.A. Mackenzie, C. Melios, I. Pasternak, J. Gallop, F.W. Østerberg, P. U. Jepsen, W. Strupinski, O. Kazakova, P. Bøggild, Electrical Homogeneity Mapping of Epitaxial Graphene on Silicon Carbide, ACS Appl. Mater. Interfaces. 10 (2018) 31641-31647. doi:10.1021/acsami.8b11428.

[18] T. Yager, A. Lartsev, R. Yakimova, S. Lara-Avila, S. Kubatkin, Wafer-scale homogeneity of transport properties in epitaxial graphene on SiC, Carbon 87 (2015) 409-414. doi:10.1016/j.carbon.2015.02.058.

[19] T. Ciuk, W. Strupinski, Statistics of epitaxial graphene for Hall effect sensors, Carbon 93 (2015) 1042-1049. doi:10.1016/j.carbon.2015.06.032.

[20] H. Lin, P. Braeuninger-Weimer, V.S. Kamboj, D.S. Jessop, R. Degl'Innocenti, H.E. Beere, D.A. Ritchie, J.A. Zeitler, S. Hofmann, Contactless graphene conductivity mapping on a wide range of substrates with terahertz time-domain reflection spectroscopy, Sci. Rep. 7 (2017) 1-9. doi:10.1038/s41598-017-09809-7.

[21] D.M.A. Mackenzie, P.R. Whelan, P. Bøggild, P.U. Jepsen, A. Redo-Sanchez, D. Etayo, N. Fabricius, D.H. Petersen, Quality assessment of terahertz time-domain spectroscopy transmission and reflection modes for graphene conductivity mapping, Opt. Express. 26 (2018). doi:10.1364/OE.26.009220.

[22] J.D. Buron, D.M.A. Mackenzie, D.H. Petersen, A. Pesquera, A. Centeno, P. Bøggild, A. Zurutuza, P.U. Jepsen, Terahertz wafer-scale mobility mapping of graphene on insulating substrates without a gate, Opt. Express. 23 (2015) 30721. doi:10.1364/OE.23.030721.

[23] P. Bøggild, D.M.A. Mackenzie, P.R. Whelan, D.H. Petersen, J.D. Buron, A. Zurutuza, J. Gallop, L. Hao, P.U. Jepsen, Mapping the electrical properties of large-area graphene, 2D Mater. 4 (2017) 042003. doi:10.1088/2053-1583/aa8683.

[24] P.R. Whelan, K. Iwaszczuk, R. Wang, S. Hofmann, P. Bøggild, P.U. Jepsen, Robust mapping of electrical properties of graphene from terahertz time-domain spectroscopy with timing jitter correction, Opt. Express. 25 (2017) 2725. doi:10.1364/OE.25.002725.

[25] J.D. Buron, D.H. Petersen, P. Bøggild, D.G. Cooke, M. Hilke, J. Sun, E. Whiteway, P.F. Nielsen, O. Hansen, A. Yurgens, P.U. Jepsen, Graphene conductance uniformity mapping, Nano Lett. 12 (2012) 5074-5081. doi:10.1021/nl301551a.

[26] J.D. Buron, F. Pizzocchero, B.S. Jessen, T.J. Booth, P.F. Nielsen, O. Hansen, M. Hilke, E. Whiteway, P.U. Jepsen, P. Bøggild, D.H. Petersen, Electrically continuous graphene from single crystal copper verified by terahertz conductance spectroscopy and micro four-point probe, Nano Lett. 14 (2014) 6348-6355. doi:10.1021/n15028167.

[27] K. Zou, X. Hong, J. Zhu, Effective mass of electrons and holes in bilayer graphene: Electronhole asymmetry and electron-electron interaction, Phys. Rev. B. 84 (2011) 085408. doi:10.1103/PhysRevB.84.085408.

[28] C. Hwang, D.A. Siegel, S.-K. Mo, W. Regan, A. Ismach, Y. Zhang, A. Zettl, A. Lanzara, Fermi velocity engineering in graphene by substrate modification, Sci. Rep. 2 (2012) 590. doi:10.1038/srep00590.

[29] L.J. van der Pauw, A method of measuring specific resistivity and Hall effect of discs of 
arbitrary shape, Philips Res. Reports. 13 (1958) 1-11. doi:10.1017/CBO9781107415324.004.

[30] V. Panchal, R. Pearce, R. Yakimova, A. Tzalenchuk, O. Kazakova, Standardization of surface potential measurements of graphene domains, Sci. Rep. 3 (2013) 2597. doi:10.1038/srep02597.

[31] D.W. Koon, F. Wang, D. Hjorth Petersen, O. Hansen, Sensitivity of resistive and Hall measurements to local inhomogeneities, J. Appl. Phys. 114 (2013) 163710. doi:10.1063/1.4826490.

[32] D.W. Koon, F. Wang, D.H. Petersen, O. Hansen, Sensitivity of resistive and Hall measurements to local inhomogeneities: Finite-field, intensity, and area corrections, J. Appl. Phys. 116 (2014) 133706. doi:10.1063/1.4896947.

[33] A. Cagliani, D.M.A. Mackenzie, L.K. Tschammer, F. Pizzocchero, K. Almdal, P. Bøggild, Large-area nanopatterned graphene for ultrasensitive gas sensing, Nano Res. 7 (2014) 743 754. doi:10.1007/s12274-014-0435-x.

[34] C. Melios, V. Panchal, K. Edmonds, A. Lartsev, R. Yakimova, O. Kazakova, Detection of Ultralow Concentration NO2 in Complex Environment Using Epitaxial Graphene Sensors, ACS Sensors. 3 (2018) 1666-1674. doi:10.1021/acssensors.8b00364.

[35] D.M.A. Mackenzie, K. Smistrup, P.R. Whelan, B. Luo, A. Shivayogimath, T. Nielsen, D.H. Petersen, S.A. Messina, P. Bøggild, Batch fabrication of nanopatterned graphene devices via nanoimprint lithography, Appl. Phys. Lett. 111 (2017). doi:10.1063/1.5010923. 


\section{Graphical abstract}

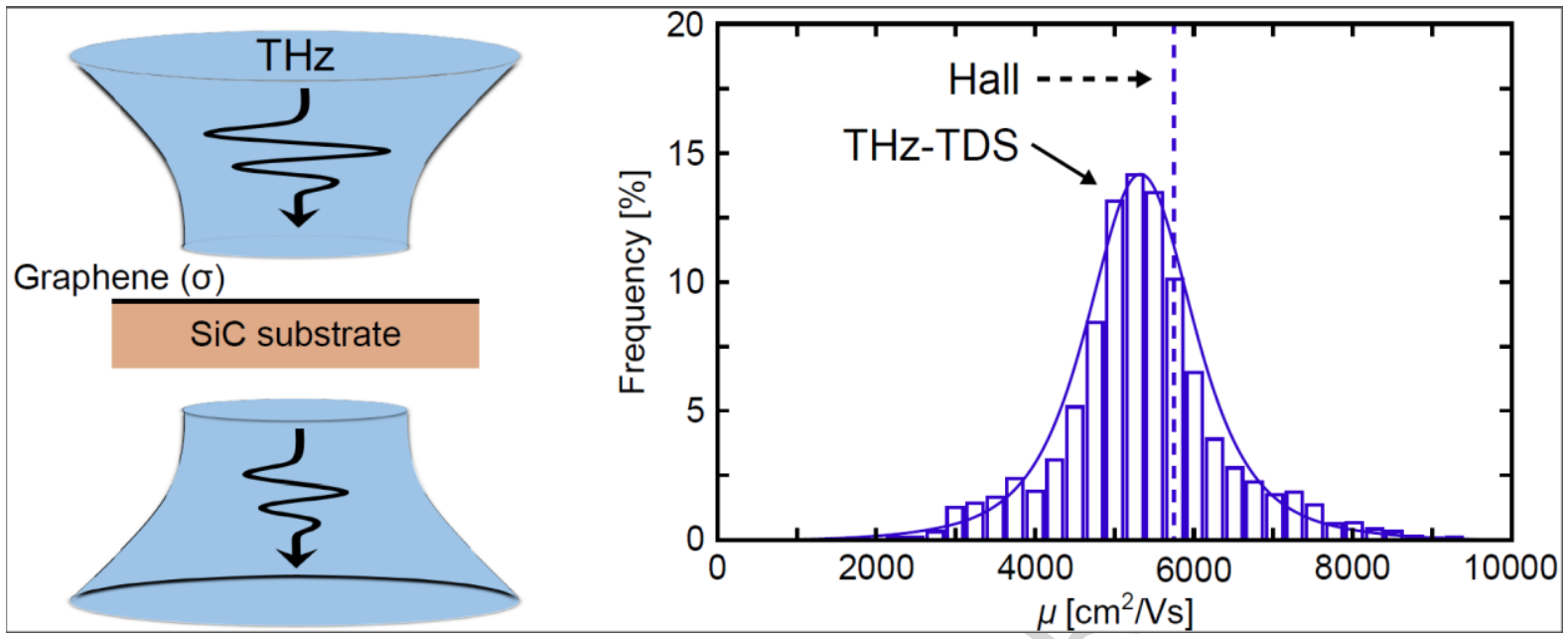

\section{Highlights}

- Terahertz time-domain spectroscopy provides non-contact measurement of the frequency dependent conductivity of thin films.

- The carrier density and mobility of graphene on silicon carbide can be spatially mapped from terahertz time-domain spectroscopy.

- Values of carrier density and mobility extracted from terahertz time-domain spectroscopy agree well with values determined by conventional Hall measurements.

- The agreement between terahertz time-domain spectroscopy and Hall measurements is best for homogeneously conducting samples. 